\title{
Working with the Community: improving the learning experience for large classes
}

SHELAGH B. WADDINGTON, National University of Ireland, Maynooth, Ireland

ABSTRACT The need for students to develop skills that are of use in the wider labour market, as well as those specifically related to their degree subjects, has been widely accepted for a considerable period of time. It has also been noted that unless these skills are practised and are contextualised they tend neither to be learned, except at the most superficial level, nor transferred to other situations where their use would be appropriate. This paper reports the use of projects extending over a number of sessions, involving working with local community groups, carried out within a discrete module specifically designed to facilitate the learning and practice of both geographical and transferable skills. The problems of providing an integrated approach to the learning of skills for a large group of students, with limited resources and in the context of timetable restrictions imposed by a two-subject degree structure, are addressed. The degree of learning perceived by the students is evaluated and suggestions are made for further development of this approach.

KEYWORDS active learning, key skills, community, group work

\section{Introduction}

Lack of apparent success in teaching students both specifically geographical and transferable skills in a designated 'practical' module has led to the development of an alternative approach in which students are involved in research collaboration with local community groups. This paper explores the background to this development, focusing on its underlying rationale, the types of skill that can be developed and the possibilities for further refinement of this strategy. A particular focus is on the difficulty of allowing students sufficient freedom to develop their learning fully within the constraints of limited time, a rigorous assessment system and with large student numbers.

For more than 15 years before the changes reported in this paper, a 'traditional' practical geography module formed a compulsory part of the 2nd year course in a two-subject BA degree. The module has always involved a commitment of 2 hours' class 


\section{S. B. Waddington}

time per week for the whole year and is currently taken by approximately 160 students. To facilitate more interaction between students and with staff, the class has always been divided into groups of approximately 50, currently requiring three sessions per week. The format prior to the changes consisted of a series of discrete classes presenting specifically geographical skills and techniques such as cartography, map interpretation and remote sensing. These skills were explained and students were then required to demonstrate their understanding by applying them in exercises using data/materials which were supplied to them for this purpose. Often these data were not related in any way to the other modules that the students were studying. After these explanatory classes it was assumed that students would apply these skills/techniques whenever they were required. However, it was also apparent that this application did not actually occur. Amongst the staff it was conceded that "the geography [generally] took second place to the techniques" (Healey, 1992, p. 9), with the result that "students saw it as being divorced from the rest of geography. It often seemed that the various techniques were learned solely for the purpose of an exercise ... and then promptly forgotten" (Hindle, 1993, p. 12). Most of the learning that took place was clearly on a very superficial level, with students merely completing the work at the time to obtain credits. When the techniques/skills were required to be used again in the final-year projects, they often had to be retaught as they were either not used correctly or had been totally forgotten. On one level the students were 'active learners' - they were not sitting passively for the whole of the time listening to exposition. However, in reality their learning was at the surface (and very temporary) - their activity was merely following a 'recipe' and not really empowering them. For learning to occur at a deeper level the students would have to be given "a marked degree of autonomy and control over the organisation, conduct and direction of the learning activity" (Kiryacou, 1991, p. 42). This would enable them to reconcile "the new information with existing knowledge" by "interacting with the new information, which is substantially reworked in the learning process" (Brown \& Knight, 1994, pp. 30-31). There was almost no evidence of this deep learning, indicated by transference of learning of the skills to other contexts within the discipline, and none that skills were being viewed as obviously applicable to more general contexts.

After reviewing the module, changes were made with a view to increasing perceived relevance. As noted by Thorley and Gregory (1994, p. 183 ) students "need to relate the activity to the reasons why they are studying at university and not be seen as an irrelevance". The exercises used for students to practise the techniques were now more clearly related to other modules within the course, providing a clear context for their use. This was certainly successful in improving motivation (and attitude) of students when material related to compulsory modules (or ones taken by a majority of the students). However, when the module was only taken by a minority of the class (e.g. climatology), this 'relevance' had a negative effect, with students feeling that work related to a module which they were not taking represented an obvious waste of their time. Efforts were made to make the class aware that the skills gained were useful in a variety of other contexts but, as students were not generally given the opportunity to put this theory into practice, it is not surprising that this suggestion was greeted with a large degree of scepticism.

At the same time as these subject-specific problems were being noted, it was becoming increasingly apparent that it was necessary to review the programme in the light of changing attitudes towards the value and purpose of an Arts degree. As Chalkley and Harwood (1998) note, "even non-vocational disciplines ... are increasingly expected to ensure that graduates embarking on a career possess the skills for which employers 
are looking" [p. 1]. Surveys such as those reported by Chalkley and Harwood (1998) revealed that the skills required included presentation, group working, information technology and data handling. It may be argued that geography is "rich in both subject-specific and generic skills" (Matthews \& Livingstone, 1996, p. 6) and also that the "general knowledge and skills engendered by most geography degrees seem widely appreciated by employers" (Walford, 1991, p. 203). There was, however, little evidence from student performance or feedback that they were conscious that their degrees were equipping them in this way. Indeed, students complained that they had not had the opportunity to develop generic skills such as team working, methods of communication (other than writing) and problem solving before they were required to use them in final-year projects. These transferable or generic skills were acquired by students (if at all) by a process of 'osmosis' and, since it was not made clear to students that any of these skills were being taught (or practised), they were generally unaware that they were supposed, at least, to be learning them.

It was acknowledged that the department did "have responsibility to taxpayers, and to students in particular, to help students to develop skills (and knowledge) which will be valued in the work place and that will help them in their personal lives" (Jenkins, 1995, p. 12). Even amongst those who felt that vocational aspects could be overemphasised to the detriment of the discipline, there was general agreement that "it certainly cannot be considered satisfactory to produce graduates who are unable to find fulfilling and rewarding careers" (Bleasdale, 1977, p. 71).

\section{How to Change?}

A number of staff members within the geography department, including the present author, felt that "wherever possible ... teaching of techniques should not be separate from the teaching of geography, as the danger of marginalising the teaching of skills in stand alone modules" (Healey, 1992, p. 16) was clearly demonstrated in the module as it existed. It would have been theoretically possible to have used an approach such as that suggested by Chalkley and Harwood (1998). This would have involved the adoption of an agreed list of key skills from which each lecturer would select a limited number that would be particularly developed through his/her module. Students would then select their options to ensure that they received a full programme. However, since choice for students was relatively limited (and in practice sometimes further constrained by timetabling difficulties), this approach would in reality have meant that there would have to be considerable overlap of skills taught or students would be unable to achieve the required balance. Class sizes would also have led to considerable time and resource management difficulties, as groups would have either to be very large or sessions would have to be repeated, placing unjustifiable burdens on participating staff. It was, therefore, agreed that within the current arrangements this was not a possible option. Advantages of retaining a designated skills module, in addition to the obvious logistical ones, were also considered to include the ability to ensure that a balanced programme was delivered, and that skills could be specifically identified and clearly assessed. This would be likely to raise student perceptions of both the presence and the importance of the skills and, as suggested by Chalkley and Harwood (1998), would also make it easier to provide evidence of what had been studied for potential employers.

As one approach to improving the likelihood of students developing the wide variety of transferable and subject-specific skills which were considered to be of importance, it 


\section{S. B. Waddington}

was decided to change the basic format of the module from a series of discrete sessions into one in which a project was carried out running over a number of sessions, with different skills being utilised within the overall context of the work. Initial teaching of skills was provided where this was necessary and opportunities were then provided for practice. Students were encouraged to use these skills whenever they felt this was appropriate.

To achieve the necessary level of interest and commitment over a sustained period, it was regarded as important that the project must relate to some genuine research, i.e. be based on a new problem, so that the information was not available already and a variety of outcomes was possible. To further improve the level of commitment, the topic should also relate, as far as possible, back to work undertaken in the first year and to other modules in the second year. In the present instance, the relevant second-year modules were urban, economic and social and cultural geography. Birnie and O'Connor (1998, p. 9) suggest that it is important that "the students' findings and their analysis of those findings, [could] be as valuable as those of a professional consultant" or those of a real researcher. There were, however, restrictions placed on this approach by limitations of resources, time and student experience. This meant that any project had to be sufficiently straightforward for students who had relatively limited experience of carrying out this type of work to be able to accomplish the task. If this could be done, then the students would be likely to "take the work seriously as a 'meaningful experience' rather than as a daunting hurdle" (Hindle, 1993, p. 11). They would have to be involved in every aspect of the project (as recommended by Moore \& Longley, 1988) and "not merely act as a docile labour force collecting or processing information on a project they have not designed, for purposes which they may not understand" (Ashworth, 1983, p. 142). A major concern was that while this type of work could be very worthwhile, students should not be exploited by staff to facilitate their own research efforts or to enable them to earn consultancy fees!

A major difficulty with using real research was the number of students who had to be involved (more than 150) who had very little, if any, experience of such work. If sufficient time, support and assistance were available, students could have identified their own projects. This would have been likely to have led to maximum commitment to the work and also to great satisfaction if the outcome was successful. Unfortunately, the amount of support and assistance required would have meant an unacceptably large investment of staff time and resources. An alternative approach, in which the lecturer identified a large number of projects from which the groups selected the one which they wished to undertake, was also rejected because it would be extremely hard for one person to devise sufficient projects. It was, therefore, decided that for this introduction to research work one large project should be carried out by the whole class, with students being divided into smaller groups to carry out the work. This approach would facilitate the progression suggested, for example, by Kent et al. (1997), in which initial work was very staff directed (as used in the first year), followed by student-centred/ staff-directed work (the present approach), leading to the final-year projects in which students had much greater autonomy. The use of groups would facilitate the development of the key social skills associated with teamwork, such as leadership and time management. They would also provide mutual support for group members and allow the different strengths and knowledge of members to be utilised. It would also provide a partial solution to the problem of individuals being reluctant to advance their own ideas or to ask questions, which occurs in tutorials and lectures as well as in project work, as noted by Habeshaw et al. (1992). As suggested by Healey et al. (1996), the use of 
groups to provide support was likely to be particularly helpful in situations where students may feel uncomfortable and lacking in confidence as they encounter (possibly for the first time) work for which there was both no pre-planned result and also a much lower degree of teacher control than that to which they were accustomed.

It was considered important by staff involved in planning the new approach that the students should receive sufficient guidance for their work as this would be the first experience for many of working on an extended project involving project planning and the use of a wide variety of skills. If students were unclear as to the purpose of their activities, they would be likely to lack confidence in carrying out the work and might also adopt a negative attitude towards the whole experience. If, however, the guidance was too rigidly defined, their involvement would also be limited because they would feel that they were merely following instructions to reach a pre-decided conclusionsomewhat like performing animals! Apart from the lack of real learning that might result, a further problem would be that students who did not appreciate the importance of what they were doing might not carry out the work as seriously as possible, leading to questionable accuracy of results. It is, however, not unknown for more senior members of the academic community to falsify results! "The challenge [was] to offer enough structure for the student to see the point ... whilst leaving enough freedom for a sense of discovery to remain" (Birnie \& O'Connor, 1998, p. 12).

Despite the possible difficulties outlined concerning involvement in staff research projects, it was decided to explore this avenue as a possible source of suitable projects. While this was being undertaken, a member of the staff was approached by the Community Council of a local town who wished to find out about travel patterns of residents with a view to improving public transport. Whilst it was not possible within the timescale available to involve the students fully in the planning of this project, they were able to be involved to some extent in all of the subsequent phases. Those who participated generally responded favourably to the experience and at least one of them stated some years later that it had been one of the outstanding memories of his work for his BA degree. The reports that were written on the data collected were generally thoughtful and creative in their suggestions. It was, therefore, decided to develop this approach further in subsequent years. This initial group also had the satisfaction of knowing that their efforts did, in fact, contribute to the decision to reopen (and indeed rebuild) the town's railway station for commuter services.

Over the past 5 years four more projects have been carried out, gradually refining and developing the approach, introducing greater student involvement at all stages and the integration of more of the 'core' skills identified for the module. Three of these studies have focused on particular local communities. Information was collected in each survey on household demographics, travel patterns and usage of local businesses and facilities. Respondents were also asked about their wishes for the future development of their towns. Specific questions relating to particular issues raised by the local community groups were also asked. The fourth project focused on the students of the university. In the other year, students had the opportunity to take part in a study of transport requirements undertaken by a group working in various EU countries. The freedom for students to participate actively in this latter project was much more restricted, as the research objectives and methodology were agreed by a coordinating group and the students had no input into the design of the questionnaire which was used. The work of this year was the only one in which serious doubts were raised about the accuracy of the results obtained, possibly reflecting this lower level of active involvement. 


\section{S. B. Waddington}

TABLE I. Project outline.

\begin{tabular}{|c|c|c|}
\hline Session & Content & Skills \\
\hline 1 & $\begin{array}{l}\text { Project briefing/initial } \\
\text { planning }\end{array}$ & $\begin{array}{l}\text { Cooperation, decision } \\
\text { making, } \\
\text { identifying aims/objectives, } \\
\text { writing, allocation of tasks, } \\
\text { listening, note taking }\end{array}$ \\
\hline 2 & Questionnaire design/testing & $\begin{array}{l}\text { Pair work, decision making, } \\
\text { reviewing question s }\end{array}$ \\
\hline 3 & Survey-data collection & $\begin{array}{l}\text { Interviewing, time } \\
\text { management, } \\
\text { organisation, map reading }\end{array}$ \\
\hline 4 & Creating a code book & $\begin{array}{l}\text { Group work, decision } \\
\text { making, ICT skills } \\
\text { (SPSS coding) }\end{array}$ \\
\hline $\begin{array}{l}5 \text { [over } \\
\text { several sessions] }\end{array}$ & $\begin{array}{l}\text { Secondary sources, e.g. } \\
\text { Census of population, } \\
\text { historic texts, trade } \\
\text { directories }\end{array}$ & $\begin{array}{l}\text { Identification of relevant } \\
\text { material, summarising, } \\
\text { abstracting }\end{array}$ \\
\hline $\begin{array}{l}6 \text { [over } \\
\text { several sessions] }\end{array}$ & Data analysis & $\begin{array}{l}\text { Interpreting tables, graphs, } \\
\text { statistics, ICT skills: } \\
\text { spreadsheets, statistical } \\
\text { packages }\end{array}$ \\
\hline 7 & Final report & $\begin{array}{l}\text { Evaluation skills [criteria for } \\
\text { assessment], presentation } \\
\text { skills: written, graphical } \\
\text { (maps, graphs), } \\
\text { interpretation of tables, } \\
\text { graphs, statistics, reaching } \\
\text { conclusions }\end{array}$ \\
\hline
\end{tabular}

\section{Project Organisation}

The general outline of the current project structure is shown in Table I. The initial project session is also the first meeting of the module. The incoming class of $150+$ has already been divided into three groups of approximately 50 to facilitate practical work. Each group meets for a two-hour session once a week for the whole academic year. As first-year classes are very large (approximately 250 students), many students entering year 2 are unknown to each other. As an initial task, students are required to form groups of four. In the first year of the projects groups were selected on a systematic basis. It would be reasonable to argue that this was the best method for selection if students were to gain the maximum learning from the experience, as in the workplace personal preference is not commonly the basis for selection of co-workers.

In practice, difficulties arose for two reasons relating to the student body and to the degree structure. A fairly high proportion of students in the university are commuters from various locations, rather than resident in the town, while others are mature students with domestic commitments. Transport and child-minding limitations make it difficult for students to attend any group meetings outside the 9 a.m. to 5 p.m. period. Within the usual work time, further constraints were imposed by the two-subject structure of the BA 
degree. Within a single group of 50-60 students, relatively small numbers were doing the same second subject. Even where there were larger numbers, options meant that they were not all free at the same time. The combination of these two problems meant that several groups found it very hard to complete any group work satisfactorily, as everything had to be completed in class time or some members of the group had to agree to complete the work without input from the rest. These problems led to very negative feedback from the more committed and interested students about the experience. In subsequent years, students have been allowed to select their own work group and far fewer problems of lack of communication and unfair workloads have arisen. Students are, however, encouraged to form groups which include both men and women and, as far as possible, as wide a mix of age and interests as possible to bring a wide range of views and ideas to each group.

A short time is allowed for them to introduce themselves before the more formal aspects of the session are begun. After this, students are provided with some basic guidance about the project and with background information about the relevant locations (see Table II for an example). For the most recent projects the briefing has included a visit to the class by members of the community group which was, in effect, commissioning the project to provide information about their group and their town. This has increased the feeling of involvement of the students and has heightened the perception of the reality of the project. The community representatives attended the first session of the week and their presentation was videotaped. The recording was then shown at the other two sessions, thus allowing all three groups to receive the same information. Any requests for further information or questions raised by the students were either answered at the first session or transmitted to the speakers and replies given as soon as possible. Slides have also been shown to provide students with a basic impression of the town.

Apart from a short introduction focusing on the general work of the module, the only structured input from the staff member to this session is a short explanation of aims and objectives and of the importance of planning in the research process. Students' attention is also drawn briefly to the first- and second-year modules which are relevant to the study. They do not at this point have a great deal of experience of the second-year modules, as this meeting takes place only 3 weeks after the start of the year. The rest of the two-hour session is devoted to the completion of the basic planning of the project by the student groups, as outlined in the section 'Working as a group' in Table II. They are required to consider their objectives and the practicalities of carrying out a questionnaire survey, in addition to producing a draft questionnaire. It has been found helpful to limit the number of questions to be asked, as this encourages a focus on the main issues, but otherwise no guidance is given on requirements at this stage. A major function of the lecturer and demonstrator for the project during this part of the session is to move from group to group providing reassurance that there are, in fact, no 'correct' answers to the tasks as nobody has collected the information before or even decided exactly what information should be collected.

The questionnaires produced in the initial session are copied for use in the second session, which takes place 2 weeks later. A draft of the questionnaire to be used in the actual survey is also produced by the lecturer before the second session using input from the students and from the community group. During the initial part of the second session, the questionnaires (both those produced by the class and the draft) are evaluated by the project groups working in pairs, with one partner being the surveyor and the other a respondent. The whole group then produces a summary listing the positive and negative aspects of the questionnaires. To avoid any possible embarrassment, the drafts produced 


\section{S. B. Waddington}

TABLE II. Initial project guidance.

Methods of Geographical Analysis: The K Study

At the end of this session you will have:

- learned about the initial stages of research planning;

- defined aims for a project;

- planned the basic outline of a research project.

Stages in carrying out a project:

- Identify the basic area of the study

- Define the problem to be studied exactly

- Decide the exact type/quantity of data required

- Decide how the data will be collected, e.g. by observation, interview

- Decide how the data will be recorded as they are collected

- Collect data

- Analyse data

- Present results of research, conclusions reached and make recommendation s for the future.

Background information about $\mathrm{K}$

$\mathrm{K} \_$is a town of 2238 inhabitants situated about $6 \mathrm{~km}$ to the west of $\mathrm{M} \_$_along the route of the former N4 and the Royal Canal. The population of the town has increase d by approximately 20 per cent (440 people) between 1991 and 1996 and is likely to continue to grow. The K and Districts Community Council is currently seeking information to facilitate decision making about current and future aspects of life in the town. Amongst these concerns are local transport and development of facilities in the town. You are a group of independent consultants commissioned to prepare a report which will help the Community Council to formulate its plans and you have already decided that a questionnair e survey must be undertaken to obtain the information. For the purposes of this exercise you may assume that you will have available a team of approximately 150 people to carry out the survey.

by the student groups are evaluated by groups meeting on another day, e.g. the Tuesday questionnaires are used by the Wednesday groups. Teaching is then provided on questionnaire design and, finally, the groups redesign the questionnaires based on their own findings and the more technical considerations. It is important that student feedback on the draft questionnaire is monitored very closely, so that questions with which they are unhappy are modified or removed from the final questionnaire. Many students have a certain degree of anxiety about meeting the public in this way and it would be unfortunate if their fears were increased because they felt the questions were unsuitable or likely to be misunderstood by respondents. An example that illustrates the importance of this monitoring arose in one project in which the community group was keen to assess non-student attitudes towards the large number of students in the town. The students generally felt that they would not receive a helpful response from many local residents if they asked this. The question was not asked in the final survey in this case as no form of words could be devised which overcame their objections. At this stage the community group also evaluates the draft and produces its own comments. The suggestions and amendments of both the students and the community group are incorporated as far as possible into the final version of the questionnaire.

As part of the meeting of the class during the following week, clear written instructions and copies of the questionnaire plus a verbal briefing of the survey procedure are given to the students. Sufficient time is allowed for discussion/questioning to take place to ensure that the survey details are fully understood by all participants.

The field surveys have taken place on a single evening about 2 weeks after the second full project session. The local community groups have facilitated the field surveys in a 
number of ways. They were all able to provide advance publicity and their involvement ensured an improved response rate from residents who generally felt that it was possible that the results would be useful to themselves and to their area's future. The preparation and administration of the surveys were also facilitated by the local groups, through the provision of maps, electoral lists and other information and also by assistance with supervision and transport at the time of the survey. In some cases they also provided financial assistance towards the costs involved. A less tangible benefit of this involvement is that it reinforces the perception of the importance of the project for the students who are reminded that it is not merely a class exercise, but of interest to others. On the evening of the survey students, working in pairs, have been allocated specific areas in which to work and have been given a definite time limit (usually about 2 hours) within which they are required to complete up to 10 surveys. They are then required to report to a central point where their questionnaires are collected and their safe return noted. Despite the relatively limited supervision of the surveyors which has been possible, follow-up visits, informal feedback and checks provided by other information sources have revealed very little evidence of students not carrying out the survey to the best of their ability.

In the session following the field survey students have been involved in creating the code book for processing the data using the data analysis package SPSS (Statistical Package for the Social Sciences). In an ideal situation they would be able to devise the code book, code the questionnaires and use SPSS themselves to analyse the data. Unfortunately, the ICT facilities currently available in the university make this impossible at present, and this session is one in which the students are not as fully involved in their research as is desirable. However, their knowledge of spreadsheets and statistical techniques is carefully related to this session and the results obtained from the data processing are related back to their experience. Data have been coded and entered into the SPSS programme by postgraduate students either as part of their own course work or as paid assistants. The survey director (the lecturer involved in the module) has then produced data in appropriate formats for use in subsequent sessions.

The work with secondary sources and the data analysis techniques (listed as sessions 5 and 6, Table I) is integrated to a great extent into other aspects of the programme of the Methods module. For example, the use and interpretation of frequency tables and data matrices are taught as part of a more general introduction to the use of EXCEL and the data used for learning basic statistical tests such as chi-square and simple correlation are derived from the survey. A major aspect of secondary source usage is that of small-area material from the census of population for the survey towns. The results from several censuses are used to provide background information for the final reports on the project, by examining changes over time. Students select the variables that they are going to employ for this purpose and work in their groups to produce the summary information that they use. This overlap of the project and other areas of the work is done primarily to facilitate the overall integration of the module and to demonstrate in a practical form the transferability of learning to different situations. It was also felt that avoiding over-concentration on the project had positive benefits in averting potential boredom.

Each student is required to produce a written report on the project (Table III). Data obtained from a number of the survey questions are provided for the students in summary form and they are required to base their main findings on these.

Limitations of access to ICT facilities and timing problems have prevented the achievement of the ideal situation, in which students would be able to carry out their 


\section{S. B. Waddington}

TABLE III. Final report guidance.

Community Survey-Final Report

Using the information containe in the tables provided, write a detailed report (1000-1500 words) describing the main findings of the $\mathrm{K} \_$Community Survey. It is expected that your report will include appropriate maps, statistics, graphs, tables, etc. The report should include:

- a short section describing the data collection methodology

- discussion of the findings

- conclusions/recommendations based on these findings

- a short critique of this method of data collection in general and of this survey in particular.

Outline what you think were both the strengths and weaknesses of the exercise.

own analysis of the raw data. In the earlier projects, guidance (Table III) was provided as to what was required for the report. More recently a much modified version of the methodology suggested by Kneale (1996) has been used to enable the students to identify what they consider should be included in a good report. In this the groups have been provided with examples of good and bad reports and asked to agree on appropriate criteria for judging them. The group results were then reported to the whole class. The students proved somewhat reluctant to make suggestions, probably reflecting their lack of experience in the task, and it was found necessary to prompt them fairly heavily. The resulting marking criteria (Table IV), therefore, include considerable input from the staff member concerned.

Reports of the findings of each survey were prepared for the community group involved by the survey director (Waddington, 1996, 1998, 1999). Material from the

TABLE IV. Final report marking criteria.

Very Good Report: Must include at least two different non-written methods of presentation, e.g. pie chart, line graph, statistical test. Findings must have been discussed (i.e. not just repeated from the handout) and conclusions/recommendation s bear clear relationship to findings, e.g. 'The building of swimming pool should be a priority as $60 \%$ of respondents suggested that this was the most desirable leisure amenity.' Grammar/spelling and presentation must be of a good standard.

$75 \%+$

Good Report: As very good, but possibly not using more than one non-written presentation technique, or all tackled but less good presentation. Possibly three sections very good with less good work on one [some attempt must have been made to answer all], e.g. conclusions, etc. not as clearly related to findings, although relevant and correct. Would be very good report but very short or extremely long, or grammar/spelling or presentation of lower standard.

$60-74 \%$

Acceptable Report: As very good written report but no use of other presentation methods, good attempt but poor presentation, etc. Limited interpretation of findings (i.e. sometimes just quote what is shown on handout without any comment). Would be good report, but considerably too short or too long.

$45-59 \%$

Poor Report: Use of no other presentation method, little or no attempt to tackle one section. Quotation of survey figures with little or no attempt at interpretation, conclusions/recommendation s only marginally related to findings. Poor presentation, grammar, etc. Would be acceptable report, but considerably too long or too short.

$35-44 \%$

Unacceptable Report: One or more sections not attempted or very incomplete, poor presentation, no use of alternative methods of presentation. Figures merely quoted, conclusions/recommendation s unrelated to findings (if presented at all). Overall lack of effort. 
students' reports has been incorporated into these and it has been planned that they should be present at the official launches of the reports. However, this has not yet proved possible as they have coincided either with examinations or have taken place during a vacation. The local media coverage of the launch and any responses, for example quotations by public figures in support of proposals emanating from the survey results (or even success of a proposal relating to some aspect of the survey), have always been reported back to the students. This outcome material has also been used as part of the overall efforts to motivate the next incoming group of students.

\section{Assessment of the Project Work}

Both to facilitate differentiation between individual students and to reward successful collaboration between group members, a number of different assessment strategies are used. Where the group members produce a common contribution then the same mark is awarded to each member, for example in the initial session. This enables some measure of recognition to be given to the importance of group skills within the project, as groups who collaborate more successfully are likely to produce better work and so gain more credit. When work is produced on an individual basis, for example the initial session using chi-square and the final report of the project, the mark varies for each person in the class. Some sessions, such as work on the census of population, involve a mixture of both group and individual work. The total mark for each student for these sessions is based on a common mark for the whole group, which is modified in the light of the individual section. The rationale for the allocation of marks is made clear to students on all occasions.

\section{Discussion}

\section{Funding Implications}

There are cost implications for carrying out this type of work. In some cases the community group was able to provide the transport for the students on the night of the survey and a venue for the coordination of the work. Unfortunately, this was not always possible. Further finance is also required for the production of the questionnaire and other materials. However, these costs are not so large as to prevent the project being undertaken. If additional funding is available, either a drink and sandwiches are provided on the night of the survey or a launch of the report is held for the students who participated, at which there is a presentation of the findings and a short social gathering. This provides a form of recognition to the students for their efforts and helps reinforce the value of their work to themselves, the wider community and to students in subsequent classes.

\section{Community Involvement}

The importance of using the local community as a resource for learning has been noted in a variety of contexts; for example Rogers (1983) suggested that the use of real problems and the provision of resources (including people within the community) facilitates real learning for students. Kakela (1979) suggested that students became more cooperative and found their work more exciting (as did the author) when they were involved in real problems and working with the community, while Larkin (1980), taking 


\section{S. B. Waddington}

a very different approach from the one reported here, noted that students showed commitment to their work when they were required to present the findings of their research on topics of community concern to members of the relevant community.

From the viewpoint of the community groups involved, the use of the students in the present projects has enabled them to obtain information they required at a cost that was within their limited means. It has also, to a limited extent, provided further benefits to the community groups. For example, the briefing sessions for the students required them to identify and to articulate their concerns about their community, and the design of the questionnaires involved their developing some data-collection skills.

There are also some drawbacks to this involvement as some members of the community groups may have agendas which are not made clear at an early stage. This has led to very time-consuming drafting and redrafting of questions to avoid the allegation that the findings were influenced by prompts provided in the wording. As also noted by Buckingham-Hadfield (1995), problems have arisen when the findings have not been what the group members were hoping for. This has led to some heated discussion about what should be included in the final report. However, to date, these discussions have ended with amicable agreement about this, and there has not been pressure to 'massage' the figures or to omit findings just because they did not support preconceived requirements. The launch of the report at a public meeting can also be somewhat problematic when there is a major public issue involved, as local representatives and members of interest groups may attempt to use the event for their own purposes. A clear agenda for the meeting and a firm chairperson are essential!

\section{Evaluating the Changes}

Student response to the projects has generally been favourable. This has been revealed over the period in informal discussion with individuals and groups, and more formally as part of a recent evaluation of the work when students from the most recent group were asked to complete a short questionnaire. Almost 50 per cent of those who responded to the questionnaire had not worked in a group before and over 90 per cent of the students felt that the experience had enhanced their ability to work in a team. Discussion revealed that where the team worked well (the majority) their confidence for undertaking final-year projects was enhanced. Those who were in less successful groups reported that they were able to avoid the more obvious problems in their subsequent work. More than 70 per cent (24) of students considered that the project had been a worthwhile experience and that their skills had been improved, while almost two-thirds ( 21 students) felt that they had learned a lot from working on the project. It is noteworthy that even those who reported that they preferred lectures to the project form of learning generally considered that they had learned a lot from the project and that their range of skills and ability to work with others had been enhanced. The aspect of relevance to the community was also viewed favourably by more than 70 per cent of the students ( 24 respondents). The strongest criticism was also voiced by a student in this respect: he/she felt that the work should have been either related to the student's own home community or to the town in which the university is situated.

Students also identified a range of skills that they considered they had learned or developed while completing the project (Fig. 1). Team working was the most commonly noted skill (by 91 per cent) followed by oral communication, identification of aims and objectives and reaching conclusions (by 78 per cent). The two least noted skills were written communication and map skills. The former would, presumably, be regarded by 


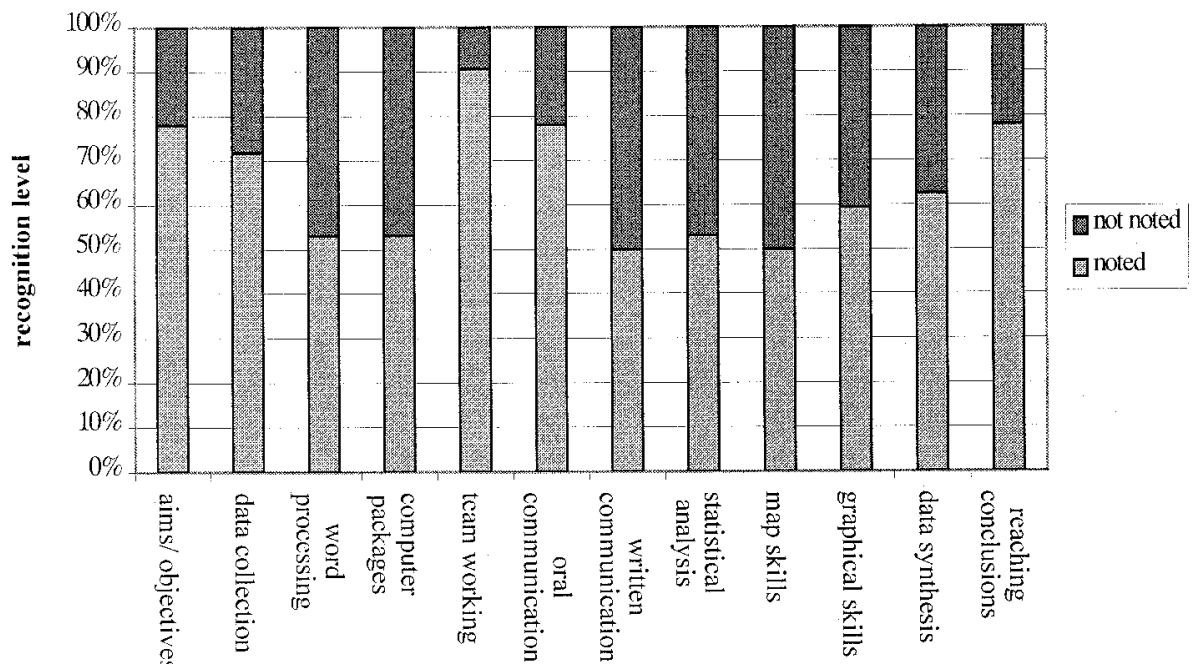

FIGURE 1. Skills developed by students.

most students as the transferable skill with which they were already most familiar and since map skills are a key geographical skill (and much used by students) the same perceived degree of familiarity would also apply to these. Additionally, map skills were used only to a limited extent during the project: during the initial planning meeting, when students were working to familiarise themselves with the location of the study settlement and during the actual survey, when they used a map to locate their survey area.

\section{Assessment Considerations}

Marks for the project have proved to be broadly comparable with those gained for other sessions within the module. Those who gained the lowest marks are invariably those who had not attended on a regular basis. The average mark for the module has remained consistently higher than that obtained for students in other modules. Indeed, almost the only cause of failure in the module has always been inconsistent attendance and/or submission of work. The mean mark has not changed greatly from before the start of the projects, while student numbers have increased considerably. Direct comparison is, however, not really valid as the type of work undertaken has changed radically in addition to the introduction of the project, with a greater variety of skills being learned and a very different overall approach.

The assessment of all aspects of the BA course, including the Methods module, is currently under review. Clearly an ability to assess work produced by themselves and others must be regarded as a useful skill which should be developed by students of geography and which must be more widely applicable and, therefore, be developed within the Methods module. One aspect of this skill that is considered to be important is enabling students to understand more clearly what is required from them. As noted by Unwin (1990, p. 34), "If students are told what markers expect from [an essay], then they can more readily learn to achieve the required types of knowledge and skills". The session in the project in which students work on the assessment criteria to be used in the final report is one strand in this overall effort which is currently in place. 


\section{S. B. Waddington}

While the students generally considered that the group aspect of the project was beneficial, some did, however, feel concerned that their marks were adversely affected by the efforts of others-something of which they had had limited (if any) past experience: only approximately half of those surveyed had done any work in groups lasting longer than one class session before the project. In the initial project an experiment was made in the use of peer assessment, with individuals being asked to rate their colleagues on a number of aspects of group working, for example the ability to work with others or to meet group deadlines. As in the group assessment reported by Healey (1997), the level of discrimination between group members was small, even when it was clear there had been grave problems with the operation of the group. Many members also expressed great reluctance to undertake the task. In subsequent years, the problem of possible unfairness was countered on a practical level by including both group and individual work within most sessions. Students therefore accepted that while the group mark might be somewhat unfair, they were prepared to accept this since the percentage of the overall mark was fairly low. Also, the final report (which counts for a higher proportion of the marks than any individual sections of the project) is assessed on an individual basis, which (as noted by Brown \& Knight, 1994) enables any unfairness to be redressed. Further possibilities, such as the use of journals or diaries, have been considered, but the need to limit the amount of work required from the students has prevented their use in these projects to date, although they are used in final-year work.

Methods of assessing those of the skills involved in the module which are currently not formally assessed are being actively considered because "if skills lie outside the summative assessment system this sends a clear signal to the students that they don't matter" (Chalkley \& Harwood, 1998, p. 16). Of particular concern is the assessment of oral skills, since these are clearly of importance and are obviously used in the project, but they are not assessed at present within this project. They are, however, assessed in other sessions of the module, and so, while options are being considered, such as a short oral presentation instead of a written report, or the use of a simulated (or genuine) public meeting about the findings is being considered, these have not been fully developed at present. If all students are to be involved, the time limitations imposed by the degree structure and timetable would make the former option very time consuming, while the latter would be very difficult to manage if it was necessary to ensure that all students participated actively.

\section{Conclusions}

In general the experiences of the projects have been positive. Student commitment to the Methods module in general has improved, and there is some evidence that skills learned in one aspect of the work are subsequently used in others, and also transferred to other areas of the course. Despite the stress involved in organising the large numbers of students and ensuring that the community group ultimately receives the report which they commission, I would recommend this approach to introducing students to practical application of geographical skills, to research and to the possibilities for interaction with the wider world.

\section{Acknowledgements}

The author gratefully acknowledges the work of the members of the successive cohorts 
of second-year students of geography, members of the MA in Geographical Analysis classes in the National University of Ireland, Maynooth, and the support and encouragement of members of the community groups who have participated in the various projects.

Correspondence: Shelagh B. Waddington, Department of Geography, National University of Ireland, Maynooth, Co. Kildare, Ireland. Tel: 3531708 3603. Email: Shelagh.Waddington@may.ie

\section{REFERENCES}

Ashworth, G. (1983) 'The use of data collection exercises in field courses', Journal of Geography in Higher Education, 7(2), pp. 141-149.

Birnie, J. \& O'CONNor, K.M. (1998) Practicals and Laboratory Work in Geography (Cheltenham, Geography Discipline Network).

BLEASDALE, S. (1977) 'After the graduation ceremony: some thoughts on geography graduate careers', Journal of Geography in Higher Education, 1(2), pp. 71-77.

Brown, S. \& KNIGHT, P. (1994) Assessing Learners in Higher Education (London, Kogan Page).

BuCKINGHAM-HADFIELD, S. (1995) Student-community partnerships: advocating community enterprise projects in Geography, Journal of Geography in Higher Education, 19(2), pp. 143-150.

ChalkLey, B. \& HARWOOD, J. (1998) Transferable Skills and Work-based Learning in Geography (Cheltenham, Geography Discipline Network).

Habeshaw, S., Habeshaw, T. \& GibBs, G. (1992) 53 Interesting Things to Do in your Seminars and Ttutorials (Bristol, Technical \& Educational Services).

Healey, M. (1992) Curriculum development and 'Enterprise': group work, resource-base d learning and the incorporation of transferable skills into a first year practical geography course curriculum, Journal of Geography in Higher Education, 16(1), pp. 7-19.

HEALEY, M. (1997) Using peer and self assessment for assessing the contribution s of individuals to a group project [on line], Cheltenham, Geography Discipline Network, http://www.chelt.ac.uk/el/philg/ gdn/abstracts/a69.htm.

Healey, M., Matthews, H., Livingstone, I. \& Foster, I. (1996) Learning in small groups in university courses: designing a core module around group projects, Journal of Geography in Higher Education, 20(2), pp. 167-180.

HINDLE, B.P. (1993) The project: putting student-controlled, small group work and transferable skills at the core of a geography course, Journal of Geography in Higher Education, 17(1), pp. 11-20.

JENKINS, A. (1995) Introduction: Linking skills, academics and disciplinary concerns in: A. JENKINS [Ed.] Developing Skill-based Curricula through the Disciplines: case studies of good practice in geography, pp. 11-15 (Birmingham, SEDA).

KAKELA, P. (1979) Remembering teaching, Journal of Geography in Higher Education, 3(1), pp. 5-12.

Kent, M., GllberTson, D.D. \& Hunt, C.O. (1997) Fieldwork in geography teaching: a critical review of the literature and approaches, Journal of Geography in Higher Education, 21(3), pp. 313-332.

Kiryakou, C. (1991) Essential Teaching Skills, Hemel Hempstead, Simon and Shuster.

Kneale, P. (1996) Organising student-centre d group fieldwork and presentations, Journal of Geography in Higher Education, 20(1), pp. 65-74.

LARKIN, R. (1980) Learning through teaching, Journal of Geography in Higher Education, 4(1), pp. 33-34.

Matthews, H. \& Livingstone, I. (1996) Geography and lifelong learning, Journal of Geography in Higher Education, 20(1), pp. 5-10.

MoORE, L. \& LongLey, P. (1988) Research and teaching functions in undergraduate project work: some integrating themes, Journal of Geography in Higher Education, 12(2), pp. 187-194.

Rogers, P. (1983) Freedom to Learn for the 1980s (Columbus, OH, Merrill).

THORLEY, L. \& Gregory, R. (1994) Present challenges, in: R. GregORY \& L. THORLEY (Eds) Using Group Based Learning in Higher Education, Ch. 26, pp. 179-186 (London, Kogan Page).

Unwin, T. (1990) 2i or not 2i? The assessment of undergraduate essays, Journal of Geography in Higher Education, 14(1), pp. 31-38.

Waddington, S.B. (1996) The Maynooth Report (Maynooth, St Patricks College). 


\section{S. B. Waddington}

Waddington, S.B. (1998) The Celbridge Report: a community study (Maynooth, National University of Ireland, Maynooth).

Waddington, S.B. (1999) The Kilcock and Districts Community Survey (Maynooth, National University of Ireland, Maynooth).

WALFORD, R. (1991) Careers for geographers: what prospects for the 1990s?, Journal of Geography in Higher Education, 15(2) 199-206. 
Copyright of Journal of Geography in Higher Education is the property of Carfax Publishing Company and its content may not be copied or emailed to multiple sites or posted to a listserv without the copyright holder's express written permission. However, users may print, download, or email articles for individual use. 